\title{
Mechanisms of apoptosis regulation by viral oncogenes in infection and tumorigenesis
}

\author{
E White ${ }^{\star, 1,2}$ \\ 1 Department of Molecular Biology and Biochemistry, Center for Advanced \\ Biotechnology and Medicine, Rutgers University, 679 Hoes Lane, Piscataway, \\ NJ 08854, USA \\ 2 Cancer Institute of New Jersey, New Brunswick, NJ 08901, USA \\ * Corresponding author: E White, Center for Advanced Biotechnology and \\ Medicine, 679 Hoes Lane, Piscataway, NJ 08854, USA. Tel: + $732235-5329$; \\ Fax: + 732 -235-5795; E-mail: ewhite@ cabm.rutgers.edu
}

Received 13.2.06; revised 14.3.06; accepted 16.3.06; published online 05.5.06 Edited by C Borner

\begin{abstract}
Apoptosis mediated by the proapoptotic BCL-2 family members BCL-2-associated X-protein (BAX) and BCL-2 antagonist/killer (BAK) is part of the antiviral response at the cellular level to limit virus replication. Viruses, in turn, have evolved to encode antiapoptotic BCL-2 homologs (v-BCL-2s) to prevent the premature death of the infected host cell to sustain virus replication. These same v-BCL-2 proteins cooperate with loss of retinoblastoma protein and p53 tumor suppressor function, by inactivating the BAX and BAK apoptotic pathway to promote epithelial solid tumor growth and resistance to chemotherapy. Analogously to infected cells, failure of apoptosis in tumors permits the survival of abnormal, damaged cells displaying chromosome instability that may further promote tumor progression. Thus, both infected cells and tumor cells require inhibition of the apoptotic host defense mechanism, the insights from which can be exploited for therapy development.

Cell Death and Differentiation (2006) 13, 1371-1377.

doi:10.1038/sj.cdd.4401941; published online 5 May 2006
\end{abstract}

Keywords: apoptosis; E1B 19K; BAX; BAK; BCL-2; BIM

Abbreviations: BAK, BCL-2 antagonist/killer; BAX, BCL-2associated X-protein; BCL-2, B-cell CLL/lymphoma 2; BIM, BCL-2-like 11; iBMK, immortal baby mouse kidney epithelial cells; MCL-1, myeloid cell leukemia sequence 1; NBK/BIK/BLK, Natural born killer/BCL-2-interacting killer/BIK-like killer; PUMA, p53 upregulated modulator of apoptosis; RB, retinoblastoma protein; v-BCL-2, viral BCL-2 homologue

\section{Introduction}

As a postdoctoral fellow in Bruce Stillman's laboratory at Cold Spring Harbor Laboratory, I was given the project to determine the function of a putative novel oncogene, E1B 19K, encoded by the DNA tumor virus adenovirus. It was determined that the left end of the viral genome, the $\mathrm{E} 1$ region, encoded the oncogenic activity of the virus. ${ }^{1,2}$ Within E1, E1A was discovered to be a transcription regulator that potently stimulated cell proliferation. These activities would soon be linked to the interaction of $E 1 A$ with the retinoblastoma tumor suppressor protein (RB) and its relatives, activation of E2Fs, and progression through the G1/S cell cycle transition. The other region within $\mathrm{E} 1, \mathrm{E} 1 \mathrm{~B}$, encoded two distinct proteins from overlapping reading frames, E1B 55K and E1B 19K. E1B $55 \mathrm{~K}$ was known to interact with the p53 tumor antigen that would soon be recognized as a tumor suppressor required for cell cycle arrest in response to DNA damage and stress. In contrast, the function of the E1B 19K protein was not known. E1B 19K had no homologs outside of adenoviruses and its interaction partners in cells were not identified. Furthermore, any function of the $\mathrm{E} 1 \mathrm{~B} 19 \mathrm{~K}$ protein associated with oncogenesis was unknown, and its function in the replication cycle of the virus had also not been determined. Our initial approach was to use viral E1B 19K mutant viruses to establish the function of the protein in productively infected cells where the life cycle of the virus was well characterized.

We, along with others, simultaneously discovered that in contrast to the wild-type virus, infection with E1B 19K mutant viruses caused the degradation of the host cell and viral DNA; a rather obscure and uninformative phenotype at the time. ${ }^{3-6}$ I realized that induction of DNA fragmentation was indicative of induction of programmed cell death by apoptosis, a virtually unknown and poorly characterized process in the 1980 s. $^{7}$ Nonetheless, making this connection suggested that the E1B $19 \mathrm{~K}$ protein might be an inhibitor of apoptosis in response to the expression of another viral gene. Indeed, adenovirus infection-induced apoptosis mapped to E1A, suggesting that E1B 19K was required to sustain the viability of the infected host cell in response to $\mathrm{E} 1 \mathrm{~A}$ expression to prevent premature termination of virus replication. ${ }^{8}$ How E1A induced and E1B $19 \mathrm{~K}$ inhibited apoptosis, and the means by which this could possibly be linked to oncogenesis, remained to be determined.

In vitro immortalization of rodent kidney epithelial cells is used to assay the oncogenic function of viral and cellular oncogenes, for which two or more cooperating genes are required for focus formation. ${ }^{9}$ Remarkably, E1A alone in this assay induces foci that regress by apoptosis, which is suppressed by E1B $19 \mathrm{~K}$ and E1B $55 \mathrm{~K} .{ }^{10,11}$ Similar findings were also reported for the cellular oncogene $c-m y c .^{12,13}$ This suggested, that just as in virus infected cells, E1A function was essential but cytotoxic, the latter of which required suppression of apoptosis. The capacity for either E1B 19K and $\mathrm{E} 1 \mathrm{~B} 55 \mathrm{~K}$ to alleviate the toxicity of E1A suggested that both $\mathrm{E} 1 \mathrm{~B}$ proteins had antiapoptotic activity.

The involvement of E1B 55K protein in the suppression of apoptosis induced by E1A suggested a possible role for $p 53$. The Oren laboratory ${ }^{14}$ reported the proapoptotic function of p53, which paved the way for the revelation that E1A induced 
p53 accumulation and p53-mediated apoptosis. ${ }^{15,16}$ Importantly, this p53-mediated apoptosis was dependent on the transcription regulation function of $\mathrm{p} 53,{ }^{17}$ and was responsible for suppressing the process of epithelial immortalization by E1A. ${ }^{15}$ Thus, apoptosis emerged as an important tumor suppression mechanism in response to oncogene activation.

Unlike E1B 55K whose activity was p53-specific, E1B 19K blocked apoptosis not only by p53 but by other diverse stimuli including death receptor signaling, suggesting that it was a general apoptosis inhibitor. ${ }^{11}$ At the time the only other antiapoptotic protein known was B-cell CLL/lymphoma 2 (BCL2), which was identified as an oncoprotein in human B-cell follicular lymphoma that functioned by sustaining cell survival. ${ }^{18,19}$ Comparison of the sequence of E1B 19K and BCL-2 revealed a low level of homology of questionable significance, although an extensive mutational analysis of conserved residues in the $\mathrm{E} 1 \mathrm{~B} 19 \mathrm{~K}$ protein indicated that this limited conservation was significant for E1B $19 \mathrm{~K}$ protein function. ${ }^{11}$ This prompted us to test for functional complementation of BCL-2 for E1B 19K in infection and epithelial cell oncogenesis.

At this point in July 1991, I contacted Stan Korsmeyer for the first time, to tell him that we thought that the E1B 19K protein functioned to inhibit apoptosis as a viral homologue of BCL-2, and we began a collaboration to test this hypothesis. This was the beginning of a long relationship that I will always cherish. We were able to demonstrate that BCL-2 expression was comparable to E1B $19 \mathrm{~K}$ expression in rescuing cells from apoptosis induced by $E 1 A$ and in the cooperation with $E 1 A$ to induce immortalization of epithelial cells. ${ }^{10}$ Although BCL-2 and E1B 19K are substantially less efficient at immortalization with $\mathrm{E} 1 \mathrm{~A}$ than direct inhibition of $\mathrm{p} 53$, this is because they only block the apoptosis function and not the cell cycle arrest function of $p 53 .^{20,21}$ The immortal clones that arise from $\mathrm{E} 1 \mathrm{~A}$ plus either BCL-2 or E1B $19 \mathrm{~K}$ are likely escape mutants that additionally overcome the p53-mediated cell cycle arrest function. BCL-2 also blocked apoptosis induced by p53 as did E1B 19K, and functionally complemented an E1B 19K adenovirus deletion mutant allowing sustained virus replication without apoptosis. ${ }^{17,20-22}$ These findings helped to demonstrate the comparable function of viral and cellular BCL-2 family members, thus crystallizing the central role of apoptosis in viral pathogenesis and in epithelial oncogenesis. $^{23}$ We now know there are subtle but important differences in the mechanisms by which E1B 19K and BCL2 inhibit apoptosis in the BCL-2 associated X-protein (BAX) and $B C L-2$ antagonist/killer (BAK) pathway that are likely related to their heritage as viral versus cellular proteins.

\section{Discussion}

\section{E1B 19K blocks apoptosis by binding to and inhibiting BAX and BAK}

To address the molecular mechanism by which the E1B $19 \mathrm{~K}$ protein inhibited apoptosis, we performed a yeast two-hybrid screen to identify cellular E1B $19 \mathrm{~K}$ interacting proteins. We identified $\mathrm{BAX},{ }^{24}$ a protein that had been identified as a proapoptotic BCL-2 interacting protein in the Korsmeyer laboratory ${ }^{25}$; natural born killer/BCL-2-interacting killer/BIKlike killer (NBK/BIK/BLK), a proapoptotic protein and the first
BH3-only protein to be identified 26 ; and lamin $A$, which is involved in localization of E1B $19 \mathrm{~K}$ to the nuclear envelope. ${ }^{27}$ Other groups identified proapoptotic BAK as an E1B 19K and $B C L-2$ interacting protein ${ }^{28-30}$ and there are a number of other joint E1B 19K/BCL-2 interacting proteins that remain poorly characterized. ${ }^{31}$ These and other findings revealed that the BCL-2 family of proteins consists of proapoptotic and antiapoptotic members that are regulated by functional antagonism through protein-protein interactions. ${ }^{32,33}$ Binding specificity between the $\mathrm{BH} 3$ of one and recipient hydrophobic binding pocket of another BCL-2 family member largely regulates these protein interactions. ${ }^{34,35}$

\section{E1B 19K preferentially inhibits activated BAX and BAK}

As our understanding of these protein-protein interactions among BCL-2 family members evolved, some interesting distinctions between E1B $19 \mathrm{~K}$ and BCL-2 were uncovered: E1B 19K primarily functions as a BAX and BAK antagonist, whereas BCL-2 is more commonly associated with inhibition of $\mathrm{BH} 3$ - only proteins upstream of $\mathrm{BAX}$ and BAK. ${ }^{23}$ With the exception of NBK/BIK/BLK, the E1B 19K protein does not bind any of the other $\mathrm{BH} 3-o n l y$ proteins examined so far that are known to bind BCL-2. The clearest example is the BH3-only protein BID, which binds and is inhibited by BCL-2 $2^{36-40}$ whereas E1B 19K does not bind or inhibit BID, but rather binds and inhibits activated BAX and BAK downstream of BID. ${ }^{41-43}$ The $\mathrm{BH} 3$ of $\mathrm{BAX}$ is sufficient for $\mathrm{E} 1 \mathrm{~B} 19 \mathrm{~K}$ protein interaction suggesting that $\mathrm{E} 1 \mathrm{~B} 19 \mathrm{~K}$ acts as a $\mathrm{BH} 3$ receptor in cells following a change in the conformation of $B A X$ that exposes the $\mathrm{BH} 3$ binding domain. ${ }^{23,24}$ Whether BAX and/or BAK are inhibited by E1B $19 \mathrm{~K}$ depends on the specific apoptotic pathway.

\section{E1B 19K inhibits BAX and BAK in death receptor-mediated apoptosis}

In death receptor signaling of apoptosis, caspase-8 cleaves BID to active tBID that binds to and conformationally activates both BAX and BAK. This change in the conformation of BAX is associated with its translocation from the cytosol to mitochondrial membranes where BAK is already localized. Joint BAX and BAK activation causes BAX-BAK complex formation and oligomerization that renders the outer mitochondrial membrane permeable, causing the release of cytochrome $c$ and second mitochondria-derived activator of caspase/Direct IAP binding protein with low $\mathrm{pl}$ that stimulate caspase-9 and -3 activation producing apoptosis. E1B $19 \mathrm{~K}$ binds BAX and BAK following their conformational activation by tBID, which blocks their oligomerization, the release of proapoptotic mitochondrial proteins, caspase activation, and apoptosis. ${ }^{41-43}$ Interestingly, E1B 19K expression in infected cells does not block caspase-8 activation upstream of BAX and BAK. Rather, E1B $19 \mathrm{~K}$ interrupts the processing of caspase- 9 allowing its cleavage by caspase- 8 but not by caspase- 3 , because caspase- 3 is downstream of BAX and BAK. ${ }^{41}$ These events all occur under the physiological conditions of productive adenovirus infection rendering infected cells resistant to death receptor-mediated apoptosis, a critically important antiviral immune surveillance mechanism (Figure 1). 


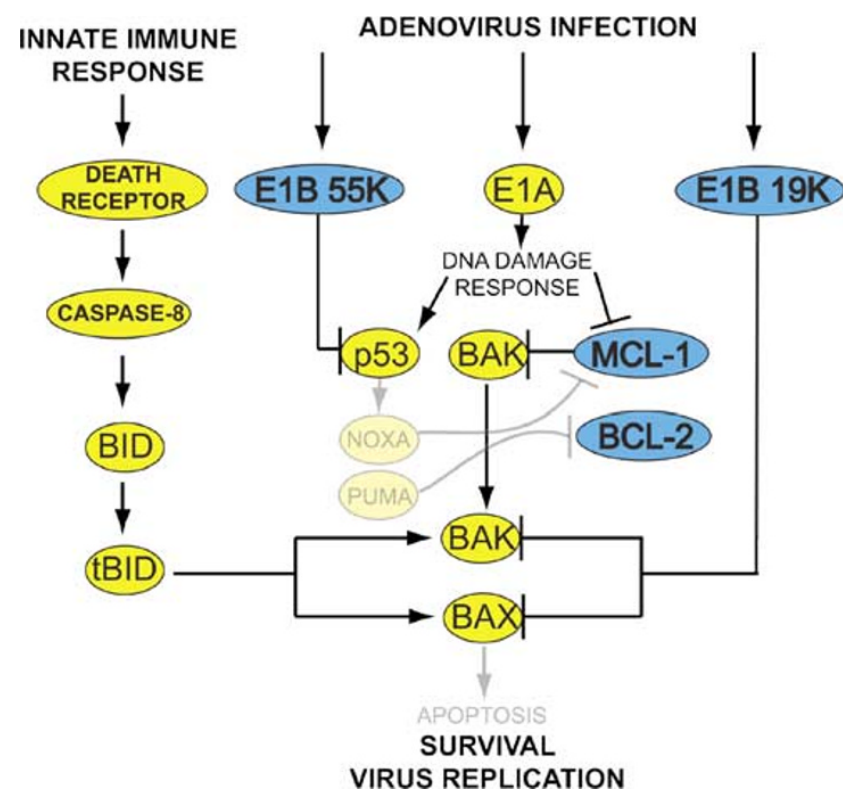

Figure 1 Regulation of apoptosis in adenovirus-infected cells. Adenovirus infection and $\mathrm{E} 1$ expression produces the three oncoproteins of the virus, $\mathrm{E} 1 \mathrm{~A}$, E1B 55K and E1B 19K ${ }^{1,2}$ Yellow symbols indicate proapoptotic, blue symbols indicate antiapoptotic function, and faded symbols indicate failed signaling events. E1A induces a cellular DNA damage response that results in $p 53$ accumulation, which can induce apoptosis through transcriptional upregulation of the BH3-only proteins PUMA and NOXA. ${ }^{68}$ The E1B $55 \mathrm{~K}$ protein binds $\mathrm{p} 53$ inhibiting its apoptotic and also growth arrest functions. ${ }^{1,2}$ Induction of a DNA damage response by $\mathrm{E} 1 \mathrm{~A}$ also triggers the proteasome-mediated degradation of the BAK inhibitor MCL-1. ${ }^{55}$ E1B $19 K$ binds BAK and inhibits apoptosis. In the absence of BAK, BAX can functionally substitute for BAK and the E1B 19K protein can also bind and inhibit activated $B A X{ }^{44}$ In death receptor-mediated apoptosis where both BAX and BAK are activated, E1B 19K binds and inhibits both BAX and BAK. ${ }^{41-43}$ Inhibition of this BAX and BAK pathway for apoptosis extends the survival of infected cells to the end of the replication cycle thereby facilitating virus production

\section{Apoptosis induced by viral infection is blocked primarily by E1B 19K inhibiting BAK}

In infected cells where the death stimulus is E1A expression, BAK is preferentially activated, and E1B $19 \mathrm{~K}$ binds BAK thereby preventing BAX activation, BAX-BAK complex formation and oligomerization, the release of proapoptotic mitochondrial proteins, caspase activation and apoptosis. ${ }^{44}$ In the absence of BAK, however, BAX can functionally substitute, again creating the necessity for E1B $19 \mathrm{~K}$ to inhibit both BAX and BAK (Figure 1). Cells that lack both BAX and BAK but not BAX or BAK are resistant to apoptosis induced by death receptor signaling and also to $\mathrm{E} 1 \mathrm{~A}$ during productive virus infection. Thus, complete complementation of an E1B $19 \mathrm{~K}$ deletion mutant is achieved by deficiency in both BAX and BAK (Figure 2). ${ }^{44,45}$

BAX and BAK are the essential core proapoptotic regulators in cells, and viruses have apparently evolved antiapoptotic functions that target this pivotal chokepoint in apoptosis signal transduction to provide the infected cell with a broad and robust defect in apoptosis. Indeed, adenovirus is not the only virus family to encode a BAX and BAK antagonist. Poxviruses and herpesviruses have since been found to encode BAX and/or BAK BH3-interacting and inhibitory proteins ${ }^{46-52}$ some of which are BCL-2 homologs, and some not. Still other viruses encode BCL-2 homologs whose mechanism of action has yet to be determined. ${ }^{23}$ The critical nature of inhibition of the apoptotic pathway by viruses is exemplified by the fact that many viruses also encode alternative and overlapping mechanisms to inhibit caspases upstream and downstream of BAX and BAK. ${ }^{53}$ These antiapoptotic functions facilitate vibus replication, reactivation from latency, persistent infection, and immune evasion. ${ }^{23}$ Thus, apoptosis is one component of the host's armamentarium to defeat viral infection. Viruses have, in turn, selectively evolved mechanisms to thwart this defense, and many of these mechanisms of virus/host interactions parallel those that occur between the tumor and host during oncogenesis.

\section{E1A induces a DNA damage response that eliminates the BAK chaperone MCL-1}

Once it was understood how apoptosis is inhibited by the E1B $19 \mathrm{~K}$ protein in infected cells, we turned our attention to the mechanism by which $\mathrm{E} 1 \mathrm{~A}$ activated apoptosis. E1A sensitizes cells to death receptor-mediated apoptosis by preventing the NF- $\kappa$ B-dependent induction of the caspase-8 inhibitory protein C-FLIP, which may contribute to the sensitivity of infected cells to apoptosis in vivo. ${ }^{54}$ Screening BCL-2 family members for functional modulation by $\mathrm{E} 1 \mathrm{~A}$ during productive virus infection in vitro revealed that $\mathrm{E} 1 \mathrm{~A}$ is responsible for inducing the complete elimination of the antiapoptotic BCL-2 family member myeloid cell leukemia sequence 1 (MCL-1). ${ }^{55}$ MCL-1 elimination is required for apoptosis induction during infection, ${ }^{55}$ similar to the role of MCL-1 in the apoptotic response to DNA damage. ${ }^{56} \mathrm{E} 1 \mathrm{~A}$ induces a DNA damage response, which accounts not only for the proteasomemediated degradation of MCL-1, but also for the accumulation of p53, which necessitates the inhibitory function of the E1B $55 \mathrm{~K}$ protein. In healthy, uninfected cells, MCL-1 is bound to BAK, thereby suppressing the proapoptotic function of BAK. ${ }^{55}$ Elimination of MCL-1 by E1A expression during infection is required for BAK release from MCL-1 and for BAK activation, but E1B 19K-BAK interaction blocks apoptosis. ${ }^{55}$ Thus, E1B $19 \mathrm{~K}$ can be thought of as a functional homolog of cellular MCL-1 (Figure 1). Infection with other DNA viruses may similarly provoke a DNA damage response and MCL-1 elimination, perhaps through induction of replication stress or owing to the presence of viral DNA. MCL-1 elimination in response to viral gene expression may explain the evolution of BAX and BAK inhibitors encoded by the viral genomes of DNA viruses.

\section{Apoptosis regulation in oncogenesis and chemotherapeutic response}

As predicted by the function of the viral oncogenes, epithelial tumorigenesis requires inhibition of the RB, p53, and BAX/ BAK pathways. E1A or C-MYC expression must be coupled to p53 inactivation for cellular immortalization, whereas tumorigenesis additionally requires inhibition of p53-independent apoptosis. ${ }^{57}$ Activation of this p53-independent apoptotic pathway is linked to the induction of metabolic stress owing 


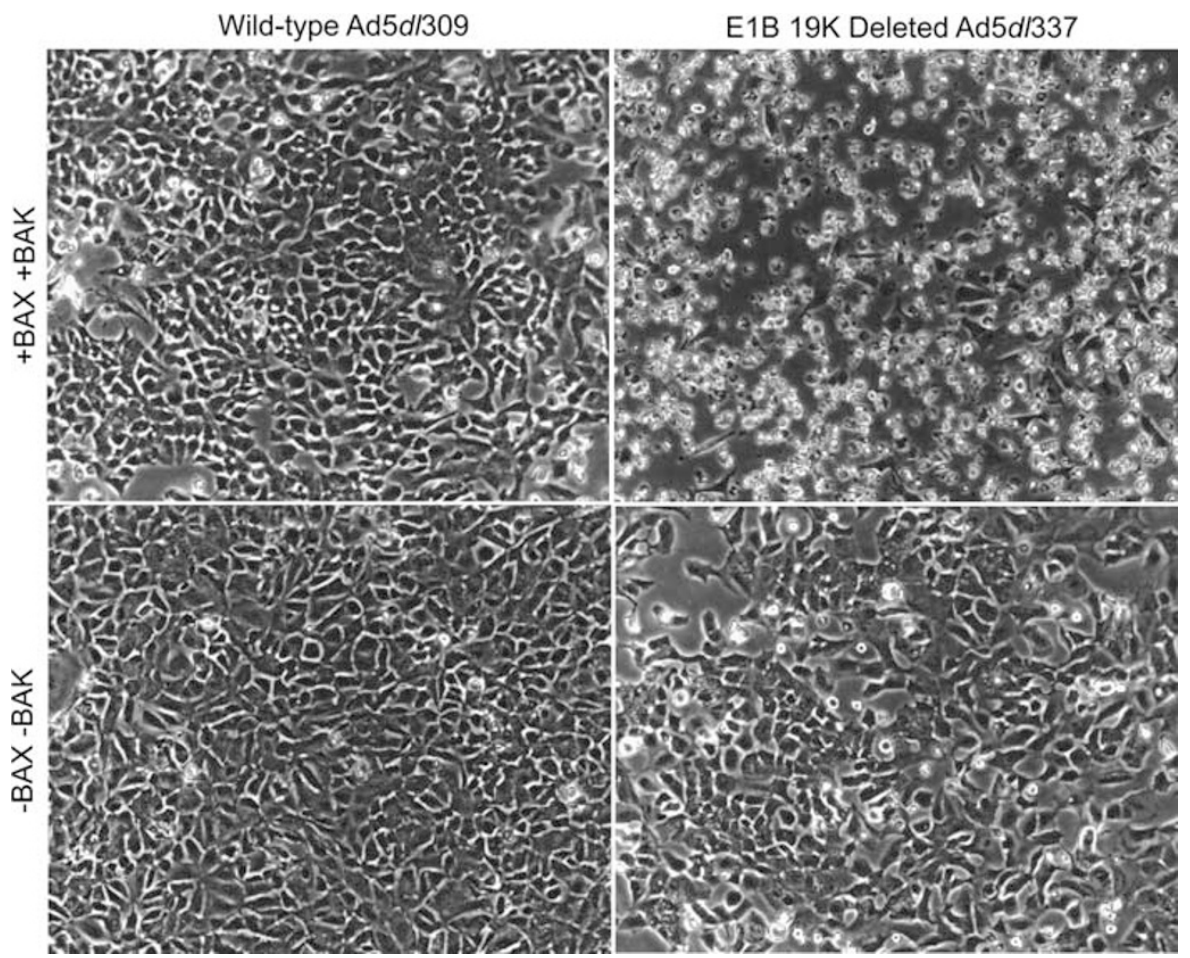

Figure 2 BAX and BAK deficiency rescues apoptosis and complements infection with an E1B 19K viral mutant. BAX and BAK expressing (top) and BAX and BAKdeficient (bottom) iBMK cells were infected with either the wild-type E1B 19K expressing (Ad5d/309) or the E1B 19K deletion mutant (Ad5d/337) adenoviruses. Note the massive cytopathic effect (apoptosis) only in the BAX and BAK-expressing cells infected with the E1B 19K mutant virus and the complementation of the E1B 19K mutant virus by $\mathrm{BAX}$ and $\mathrm{BAK}$-deficient cells. This induction of apoptosis is dependent on E1A expression and requires BAX or BAK. Expression of the E1B 19K protein, which binds and inhibits BAX and BAK, is sufficient to rescue apoptosis induction during infection thereby enhancing virus replication

to ischemic conditions in the tumor microenvironment. ${ }^{58}$ All tumors endure metabolic stress, either before acquisition of a blood supply during tumor establishment, or owing to episodic collapse of tumor vasculature in established tumors. Defects in apoptosis allow tumor cells to survive these intermittent periods of deprivation; however, these 'undead' tumor cells show signs of chromosome instability. ${ }^{58}$ Thus, surviving metabolic stress in vivo may promote tumor growth, but it may be the survival of these damaged, chromosomally unstable cells that is the true cause of tumor progression (Figure 3).

Deficiency in BAX and BAK or the gain-of-function of BCL-2 or E1B $19 \mathrm{~K}$ promotes epithelial tumorigenesis in baby mouse kidney epithelial cells rendered immortal by RB and p53 pathway inactivation (immortal baby mouse kidney epithelial cells (iBMK) cells). ${ }^{58}$ Interestingly, BCL-2 or E1B 19K have no additional tumor-promoting activity in the absence of $B A X$ and BAK. $^{58}$ This genetic epistasis demonstrates that BCL-2 and E1B 19K function in the BAX and BAK apoptotic pathway to block apoptosis and promote the growth of epithelial carcinomas (Figure 3).

\section{Identification of BIM as an epithelial tumor suppressor}

To determine the apoptotic signaling events upstream of BAX and BAK that are responsible for tumor suppression, we screened immortal epithelial cells with defined deficiencies in
$\mathrm{BH} 3-$ only proteins for the ability to overcome the block to tumor growth. Whereas p53 upregulated modulator of apoptosis (PUMA), NOXA, and NBK/BIK/BLK deficiency does not enable tumorigenesis, BCL-2-like 11 (BIM) deficiency confers the capacity for tumor growth. ${ }^{59} \mathrm{BIM}$ is a potent $\mathrm{BCL}-2$ antagonist in vivo, ${ }^{60}$ and $\mathrm{BIM}$ inactivation is the mechanism of apoptosis inhibition by the MAP kinase pathway, which phosphorylates BIM causing its targeted degradation in proteasomes (Figure 3). ${ }^{59} \mathrm{BIM}$ is also the determinant for taxane responsiveness; therefore, the loss or inactivation of BIM promotes not only tumor growth, but also resistance to taxane-mediated chemotherapy. ${ }^{59}$ In tumors, where BIM function is compromised by activation of the MAP kinase pathway, proteasome inhibitors (Velcade, for example) rescue the therapeutic response to taxanes to promote tumor regression (Figure 3 ). Thus determining the mechanism of apoptosis regulation and how common mutations found in human tumors disable apoptosis can produce a rational, tumor genotype specific approach to chemotherapy. ${ }^{61}$

\section{Conclusions}

These studies revealed that the proapoptotic BAX and BAK function as an antiviral response to limit virus replication, and that viral countermeasures include the evolution of BAX and BAK inhibitors encoded by viral BCL-2 homolog ( $v-B C L-2)$ proteins. This raises the possibility of therapeutic targeting of $\mathrm{v}-\mathrm{BCL}-2$ proteins as a means to induce apoptosis of infected 


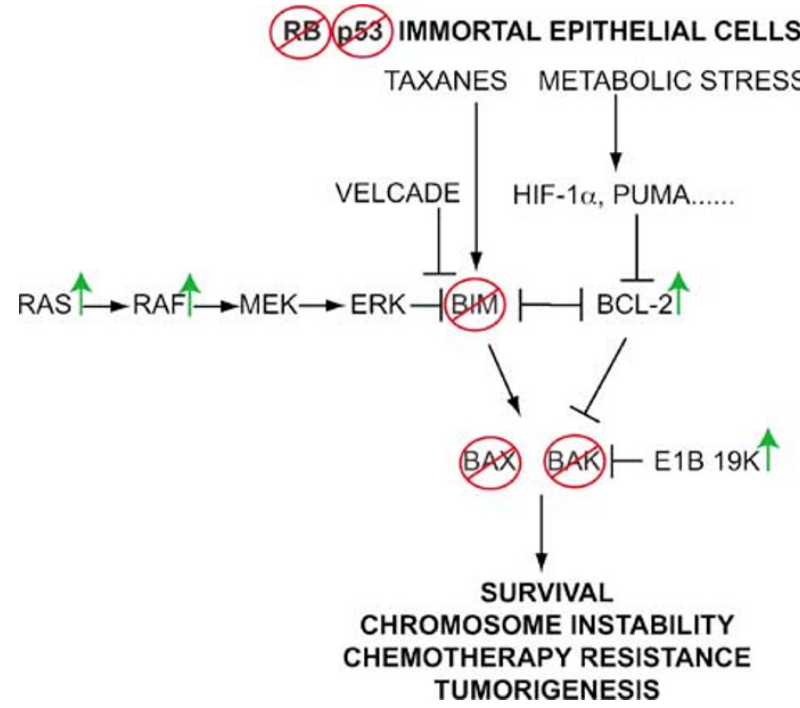

Figure 3 Regulation of apoptosis in epithelial tumorigenesis. The red crossedout circles indicate deficiency mutations and the green arrows indicate gain-offunction mutations. Inactivation of the RB and p53 pathways renders primary mouse epithelial cells immortal, however, as they retain a robust p53independent apoptotic response, they are not tumorigenic. ${ }^{9,57}$ In vivo tumor cell apoptosis induction is linked to ischemic conditions in the tumor microenvironment before angiogenesis that cause upregulation of $\mathrm{HIF-} 1 \alpha$ PUMA, and likely many other gene products. ${ }^{58}$ PUMA is a BCL-2 antagonist that may contribute to apoptosis induction; however, PUMA deficiency alone is insufficient to enable tumor growth. Deficiency in BIM enables tumorigenesis, and $\mathrm{BIM}$ and $\mathrm{BCL}-2$ are functionally antagonistic. ${ }^{59}$ Upregulation of $\mathrm{BCL}-2$ promotes apoptosis resistance and enables tumor growth. ${ }^{59}$ Taxanes induce dramatic upregulation of BIM, which is required for taxane-mediated apoptosis. RAS or RAF activation in tumor cells causes ERK-dependent phosphorylation of BIM, which targets BIM for degradation by the ubiqutin/proteasome pathway. ${ }^{59}$ RAS or RAF activation have no additional antiapoptotic activity in the absence of BIM demonstrating genetic epistasis, indicating that inactivation of BIM is the mechanism by which the MAP kinase pathway blocks apoptosis and produces resistance to taxanes. ${ }^{59}$ Proteasome inhibitors such as Velcade block BIM degradation by the MAP kinase pathway and restore taxane-mediated apoptosis. $\mathrm{BIM}$ and BCL-2 act upstream of and require BAX and BAK function to regulate apoptosis. BIM cannot induce apoptosis in the absence of BAX and BAK, and $\mathrm{BCL}-2$ has no tumorigenic activity in $\mathrm{BAX}$ and $\mathrm{BAK}$ deficient cells. ${ }^{58}$ This genetic epistasis demonstrates that BIM and BCL-2 function in the BAX and BAK pathway. The v-BCL-2 E1B $19 \mathrm{~K}$ binds and inhibits BAX and BAK and the tumorigenic activity of E1B $19 \mathrm{~K}$ requires $\mathrm{BAX}$ and $\mathrm{BAK}{ }^{58}$ Thus, inactivation of this BAX and BAK apoptotic pathway by any of these mechanisms results in tumorigenic epithelial cells that manifest chromosome instability that can promote tumor progression, and chemoresistance that can confound treatment response

cells to inhibit virus production. These same regulatory mechanisms in virus-infected cells have also been informative with regard to oncogenesis. The viral oncogenes that are essential for epithelial tumorigenesis target three critical pathways in oncogenesis: that controlled by RB, p53, and BAX/BAK (Figures 1 and 3). Indeed, the ability of replicationcompetent mutant adenoviruses with defective antiapoptotic function to promote selective tumor cell killing is being exploited therapeutically. ${ }^{62-65}$

Many approaches for cancer therapy rely on inducing apoptosis of tumor cells, and understanding the mechanisms by which apoptosis is regulated is essential for therapeutic success. Deciphering the role for BIM in tumorigenesis and the response to taxanes is just one example of how defining the mechanisms by which mutations in human tumors prevent the apoptotic response can reveal a rational approach to chemotherapy. Similarly, determining the mechanisms by which chemotherapeutic drugs activate the apoptotic response in tumors and how this is impacted by the tumor genotype will be informative. ${ }^{61}$

Many important issues related to apoptosis regulation in infected cells still remain to be addressed. For example, in virus-infected cells MCL-1 elimination is required but not sufficient for apoptosis indicating that there is a step missing in the activation of BAK, although tBID is apparently not involved. ${ }^{55}$ It is also not known how MCL-1 releases $\mathrm{BAK}$; however, one candidate is the $\mathrm{BH}$-only protein, NOXA that performs this function in other physiological settings. ${ }^{66}$ Alternatively, NBK/BIK/BLK might be expected to play a role in virus-mediated apoptosis as it is targeted for inhibition by the E1B 19K protein. Our panel of BH3-only-deficient iBMK cells may be helpful in this regard. Finally, it is interesting to speculate that BAK may facilitate activation of BAX, but how BAX gets activated in the absence of BAK is not known.

In oncogenesis, defects in apoptosis in tumors allow cells to survive metabolic and other stresses that can lead to preservation of cells with chromosome instability. ${ }^{58}$ We need to know how this chromosomal instability occurs and contributes to tumor progression. Although BIM plays a major role in suppression of epithelial tumorigenesis, it is not clear how BIM becomes activated and if it has a direct or indirect role in the activation of BAX and BAK. The BH3-only protein PUMA is induced by metabolic stress in vitro and in tumors in vivo but it is not required for tumor suppression, nor is NBK/ $\mathrm{BIK} / \mathrm{BLK}$ or NOXA ${ }^{59} \mathrm{~A}$ more complete understanding of the different apoptotic stresses and the role of $\mathrm{BH}$-only proteins in regulating the $\mathrm{BCL}-2$ family response in tumors will be informative. Furthermore, we need to identify alternate mechanisms for induction of cell death in tumors when apoptosis fails. Tumor cells can die by necrosis and mitotic catastrophe, and tumor cell survival may also be linked to autophagy. How tumor cells can be induced to die by alternative mechanisms and how this can be brought about therapeutically will be of great importance. ${ }^{67}$

\section{Acknowledgements}

I thank Thomasina Sharkey for assistance with preparation of the manuscript and members of the White Laboratory Kurt Degenhardt, Robin Mathew, and Christina Karp for their insightful comments.

\section{References}

1. Berk AJ (2005) Recent lessons in gene expression, cell cycle control, and cell biology from adenovirus. Oncogene 24: 7673-7685.

2. White $E$ (2001) Regulation of the cell cycle and apoptosis by the oncogenes of adenovirus. Oncogene 20: 7836-7846.

3. Pilder S, Logan J and Shenk T (1984) Deletion of the gene encoding the adenovirus 5 early region $1 \mathrm{~B} 21000$-molecular weight polypeptide leads to degradation of viral and cellular DNA. J. Virol. 52: 664-671.

4. Subramanian T, Kuppuswamy M, Gysbers J, Mak S and Chinnadurai G (1984) $19-\mathrm{kDa}$ tumor antigen coded by early region $\mathrm{E} 1 \mathrm{~b}$ of adenovirus 2 is required for efficient synthesis and for protection of viral DNA. J. Biol. Chem. 259: 1177711783.

5. Takemori N, Cladaras C, Bhat B, Conley AJ and Wold WSM (1984) cyt gene of adenovirus 2 and 5 is an oncogene for transforming function in early region 
E1B and encodes the E1B 19000 -molecular-weight polypeptide. J. Virol. 52 : 793-805.

6. White E, Grodzicker T and Stillman BW (1984) Mutations in the gene encoding the adenovirus early region 1B 19000-molecular weight tumor antigen cause the degradation of chromosomal DNA. J. Virol. 52: 410-419.

7. Wyllie AH (1980) Cell death: the significance of apoptosis. Int. Rev. Cytol. 68 : 251-306.

8. White E, Cipriani R, Sabbatini P and Denton A (1991) The adenovirus E1B 19 kilodalton protein overcomes the cytotoxicity of E1A proteins. J. Virol. 65: 2968-2978.

9. Degenhardt $K$ and White $E$ (2006) A mouse model system to genetically dissect the molecular mechanisms regulating tumorigenesis. Clin. Cancer Res. (In press).

10. Rao $L$, Debbas $M$, Sabbatini $P$, Hockenberry $D$, Korsmeyer $S$ and White $E$ (1992) The adenovirus E1A proteins induce apoptosis which is inhibited by the E1B 19K and Bcl-2 proteins. Proc. Natl. Acad. Sci. USA 89: 7742-7746.

11. White E, Sabbatini P, Debbas M, Wold WSM, Kusher DI and Gooding L (1992) The 19-kilodalton adenovirus E1B transforming protein inhibits programmed cell death and prevents cytolysis by tumor necrosis factor alpha. Mol. Cell. Biol. 12: 2570-2580

12. Evan GI, Wyllie AH, Gilbert CS, Littlewood TD, Land H, Brooks M, Waters CM, Penn LZ and Hancock DC (1992) Induction of apoptosis in fibroblasts by c-myc protein. Cell 69: 119-128.

13. Fanidi A, Harrington EA and Evan G (1992) Cooperative interaction between cmyc and bcl-2 proto-oncogenes. Nature (London) 359: 554-556

14. Yonish-Rouach E, Resnitzky D, Lotem J, Sachs L, Kimchi A and Oren M (1991) Wild-type $p 53$ induces apoptosis of myeloid leukaemic cells that is inhibited by interleukin-6. Nature (London) 352: 345-347.

15. Debbas $M$ and White $E$ (1993) Wild-type $p 53$ mediates apoptosis by $E 1 A$ which is inhibited by E1B. Genes Dev. 7: 546-554.

16. Lowe S and Ruley HE (1993) Stabilization of the p53 tumor suppressor is induced by adenovirus-5 E1A and accompanies apoptosis. Genes Dev. 7: 535545 .

17. Sabbatini $P$, Lin J, Levine AJ and White E (1995) Essential role for p53mediated transcription in E1A-induced apoptosis. Genes Dev. 9: 2184-2192.

18. Hockenbery D, Nuñez G, Milliman C, Schreiber RD and Korsmeyer S (1990) $\mathrm{Bcl}-2$ is an inner mitochondrial membrane protein that blocks programmed cell death. Nature (London) 348: 334-336.

19. Vaux DL, Cory S and Adams TM (1988) Bcl-2 promotes the survival of haemopoietic cells and cooperates with c-myc to immortalize pre-B cells. Nature (London) 335: 440-442.

20. Chiou S-K, Rao L and White E (1994) Bcl-2 blocks p53-dependent apoptosis. Mol. Cell. Biol. 14: 2556-2563.

21. Sabbatini P, Chiou S-K, Rao L and White E (1995) Modulation of p53-mediated transcriptional repression and apoptosis by the adenovirus E1B 19K protein. Mol. Cell. Biol. 15: 1060-1070

22. Chiou S-K, Tseng CC, Rao L and White E (1994) Functional complementation of the adenovirus $\mathrm{E} 1 \mathrm{~B} 19 \mathrm{~K}$ protein with $\mathrm{BCl}-2$ in the inhibition of apoptosis in infected cells. J. Virol. 68: 6553-6566.

23. Cuconati $A$ and White $E$ (2002) Viral homologues of Bcl-2: role of apoptosis in the regulation of virus infection. Genes Dev. 16: 2465-2478.

24. Han J, Sabbatini P, Perez D, Rao L, Modha D and White E (1996) The E1B 19K protein blocks apoptosis by interacting with and inhibiting the p53-inducible and death-promoting Bax protein. Genes Dev. 10: 461-477.

25. Oltvai ZN, Millman CL and Korsmeyer SJ (1993) Bcl-2 heterodimerizes in vivo with a conserved homolog, Bax, that accelerates programmed cell death. Cell 74: 609-619.

26. Han J, Sabbatini P and White E (1996) Induction of apoptosis by human Nbk Bik, a BH3 containing E1B 19K interacting protein. Mol. Cell. Biol. 16: 58575864.

27. Rao L, Modha D and White E (1997) The E1B 19K protein associates with lamins in vivo and its proper localization is required for inhibition of apoptosis. Oncogene 15: 1587-1597.

28. Chittenden T, Harrington EA, O'Connor R, Flemington C, Lutz RJ, Evan Gl and Guild BC (1995) Induction of apoptosis by the Bcl-2 homologue Bak. Nature (London) 374: 733-736.

29. Farrow SN, White JHM, Martinou I, Raven T, Pun K-T, Grinham CJ, Martinou JC and Brown R (1995) Cloning of a bcl-2 homologue by interaction with adenovirus E1B 19K. Nature (London) 374: 731-733.
30. Kiefer MC, Brauer MJ, Powers VC, Wu JJ, Umansky SR, Tomei LD and Barr PJ (1995) Modulation of apoptosis by the widely distributed Bcl-2 homolgue Bak. Nature (London) 374: 736-739.

31. Boyd J, Malstrom S, Subramanian T, Venkatesh L, Schaeper U, Elangovan B, D'Sa-Eipper C and Chinnadurai G (1994) Adenovirus E1B $19 \mathrm{kDa}$ and bcl-2 proteins interact with a common set of cellular proteins. Cell 79: 341-351.

32. Adams JM (2003) Ways of dying: multiple pathways to apoptosis. Genes Dev. 17: 2481-2495

33. Danial NN and Korsmeyer SJ (2004) Cell death: critical control points. Cell 116 205-219.

34. Gelinas $\mathrm{C}$ and White $\mathrm{E}$ (2005) BH3-only proteins in control: Specificity regulates MCL-1 and BAK-mediated apoptosis. Genes Dev. 19: 1263-1268.

35. Willis SN and Adams JM (2005) Life in the balance: how BH3-only proteins induce apoptosis. Curr. Opin. Cell Biol. 17: 1-9.

36. Wang K, Yin X-M, Chao DT, Milliman CL and Korsmeyer SJ (1996) BID: a novel BH3 domain-only death agonist. Genes Dev. 10: 2859-2869.

37. Luo X, Budihardjo I, Zou H, Slaughter C and Wang X (1998) Bid, a Bcl2 interacting protein, mediates cytochrome $c$ release from mitochondria in response to activation of cell surface death receptors. Cell 94: 481-490.

38. Li H, Zhu H, Xu C-J and Yuan J (1998) Cleavage of BID by caspase 8 mediates the mitochondrial damage in the Fas pathway of apoptosis. Cell 94: 491-501.

39. Gross A, Yin X-M, Wang K, Wei MC, Jockel J, Milliman C, Erdjument-Bromage $\mathrm{H}$, Tempst $\mathrm{P}$ and Korsmeyer SJ (1999) Caspase cleaved BID targets mitochondria and is required for Cytochrome $\mathrm{c}$ release, while $\mathrm{BCL}-\mathrm{X}_{\mathrm{L}}$ prevents this release but not tumor necrosis factor-R1/Fas death. J. Biol. Chem. 274 1156-1163.

40. Wei MC, Lindsten T, Mootha VK, Weiler S, Gross A, Ashiya M, Thompson CB and Korsmeyer SJ (2000) tBid, a membrane-targeted death ligand, oligomerizes Bak to release cytochrome c. Genes. Dev. 14: 2060-2071.

41. Perez D and White $E(2000)$ TNF- $\alpha$ signals apoptosis through a Bid-dependent conformational change in Bax that is inhibited by E1B 19K. Mol. Cell 6: 53-63.

42. Sundararajan R, Cuconati $A$, Nelson $D$ and White $E$ (2001) Tumor necrosis factor- $\alpha$ induces Bax-Bak interaction and apoptosis, which is inhibited by adenovirus E1B 19K. J. Biol. Chem. 276: 45120-45127.

43. Sundararajan R and White E (2001) E1B 19K blocks Bax oligomerization and tumor necrosis factor alpha-mediated apoptosis. J. Virol. 75: 7506-7516.

44. Cuconati A, Degenhardt K, Sundararajan R, Anschel A and White E (2002) BAK and BAX function to limit adenovirus replication through apoptosis induction. J. Virol. 76: 4547-4558.

45. Degenhardt K, Sundararajan R, Lindsten T, Thompson CB and White E (2002) Bax and Bak independently promote cytochrome-c release from mitochondria. J. Biol. Chem. 277: 14127-14134.

46. Arnoult D, Bartle LM, Skaletskaya A, Poncet D, Zamzami N, Park PU, Sharpe J, Youle RJ and Goldmacher VS (2004) Cytomegalovirus cell death suppressor vM1A blocks Bax- but not Bak-mediated. Proc. Natl. Acad. Sci. USA 101: 7988-7993

47. Fischer SF, Ludwig H, Holzapfel J, Kvansakul M, Chen L, Huang DC, Sutter G, Knese $\mathrm{M}$ and Hacker $\mathrm{G}$ (2006) Modified vaccinia virus Ankara protein $\mathrm{F} 1 \mathrm{~L}$ is a novel BH3-domain-binding protein and acts together with the early viral protein E3L to block virus-associated apoptosis. Cell Death Differ. 13: 109-118

48. Loh J, Huang Q, Petros AM, Nettesheim D, van Dyke LF, Labrada L, Speck SH Levine B, Olejniczak ET and Virgin HW (2005) A surface groove essential for viral bcl-2 function during chronic infection in vivo. PLoS Pathog. 1: e10.

49. Postigo A, Cross JR, Downward J and Way M (2006) Interaction of F1L with the $\mathrm{BH} 3$ domain of Bak is responsible for inhibiting vaccinia-induced apoptosis. Cell Death Differ. (in press).

50. Su J, Wang G, Barrett JW, Irvine TS, Gao X and McFadden G (2006) Myxoma virus M11L blocks apoptosis through inhibition of conformational activation of Bax at the mitochondria. J. Virol. 80: 1140-1151.

51. Wang G, Barrett JW, Nazarian SH, Everett H, Gao X, Bleackley C, Colwill K, Moran MF and McFadden G (2004) Myxoma virus M11L prevents apoptosis through constitutive interaction with Bak. J. Virol. 78: 7097-7111.

52. Wasilenko ST, Banadyga L, Bond D and Barry M (2005) The vaccinia virus F1L protein interacts with the proapoptotic protein Bak and inhibits Bak activation. J. Virol. 79: 14031-14043.

53. Roulston A, Marcellus RC and Branton PE (1999) Viruses and apoptosis. Annu. Rev. Microbiol. 53: 577-628.

54. Perez D and White $E$ (2003) E1A sensitizes cells to TNF- $\alpha$ by down-regulating c-FLIP. J. Virol. 77: 2651-2662. 
55. Cuconati A, Mukheriee C, Perez D and White E (2003) DNA damage response and MCL-1 destruction initiate apoptosis in adenovirus-infected cells. Genes Dev. 17: 2922-2932.

56. Nijhawan D, Fang M, Traer E, Zhong Q, Gao W, Du F and Wang X (2003) Elimination of Mcl-1 is required for the initiation of apoptosis following ultraviolet irradiation. Genes Dev. 17: 1475-1496.

57. Degenhardt K, Chen G, Lindsten T and White E (2002) Bax and Bak mediate p53-independent suppression of tumorigenesis. Cancer Cell 2: 193-203.

58. Nelson D, Tan T-T, Rabson AB, Anderson D, Degenhardt K and White E (2004) Hypoxia and defective apoptosis drive genomic instability and tumorigenesis. Genes Dev. 18: 2095-2107.

59. Tan T-T, Degenhardt K, Nelson DA, Beaudoin B, Nieves-Neira W, Bouillet $P$, Villunger A, Adams JM and White $E$ (2005) Key roles of BIM-driven apoptosis in epithelial tumors and rational chemotherapy. Cancer Cell 7: 227-238.

60. Bouillet P, Cory S, Zhang LC, Strasser A and Adms JM (2001) Degenerative disorders caused by Bcl-2 deficiency prevented by loss of its BH3-only antagonist Bim. Dev. Cell 1: 645-653.

61. Tan T-T and White $E$ (2006) Therapeutic targeting of death pathways in cancer. In Programmed Cell Death in Cancer Progression and Therapy, Khosravi-Far $R$, White $E$ (eds) Springer, The Netherlands (in press).

62. Liu TC, Hallden G, Wang Y, Brooks G, Francis J, Lemoine N and Kirn D (2004) An E1B-19 kDa gene deletion mutant adenovirus demonstrates tumor necrosis factor-enhanced cancer selectivity and enhanced oncolytic potency. Mol. Ther. 9: $786-803$.

63. Liu TC, Wang Y, Hallden G, Brooks G, Francis J, Lemoine NR and Kirn D (2005) Functional interactions of antiapoptotic proteins and tumor necrosis factor context of a replication-competent adenovirus. Gene Therapy. 12: 13331346.

64. Sauthoff H, Pipiva T, Chen S, Heitner S, Cheng J, Huang YQ, Rom WN and Hay JG (2006) Modification of the p53 transgene of a replication-competent adenovirus prevents mdm2- and E1b-55kD-mediated degradation of p53. Cancer Gene Ther. (in press).

65. Schmitz M, Graf C, Gut T, Sirena DIP, Dummer R, Greber UF and Hemmi S (2006) Melanoma cultures show different susceptibility towards E1A-, E1B$19 \mathrm{kDa}$ - and fiber-modified replication-competent adenoviruses. Gene Therapy. (in press).

66. Willis SN, Chen L, Dewson G, Wei A, Naik E, Fletcher JI, Adams JM and Huang DC (2005) Proapoptotic Bak is sequestered by Mcl-1 and Bcl-xL, but not Bcl-2, until displaced by BH3-only proteins. Genes Dev. 19: 1294-1305.

67. Nelson D and White E (2004) Exploiting different ways to die. Genes Dev. 18: 1223-1226.

68. Villunger A, Michalak EM, Coultas L, Mullauer F, Bock G, Ausserlechner MJ, Adams JM and Strasser A (2003) p53- and drug-induced apoptotic responses mediated by BH3-only proteins Puma and Noxa. Science 302: 1036-1038. 